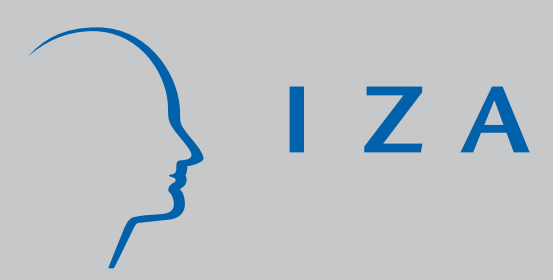

IZA DP No. 5840

Preferences for Consistency

Armin Falk

Florian Zimmermann

July 2011

Forschungsinstitut zur Zukunft der Arbeit Institute for the Study of Labor 


\title{
Preferences for Consistency
}

\author{
Armin Falk \\ University of Bonn, \\ CEPR, CESifo, DIW, MPI and IZA
}

Florian Zimmermann

University of Bonn

\section{Discussion Paper No. 5840 \\ July 2011}

IZA

P.O. Box 7240

53072 Bonn

Germany

Phone: +49-228-3894-0

Fax: +49-228-3894-180

E-mail: iza@iza.org

Any opinions expressed here are those of the author(s) and not those of IZA. Research published in this series may include views on policy, but the institute itself takes no institutional policy positions.

The Institute for the Study of Labor (IZA) in Bonn is a local and virtual international research center and a place of communication between science, politics and business. IZA is an independent nonprofit organization supported by Deutsche Post Foundation. The center is associated with the University of Bonn and offers a stimulating research environment through its international network, workshops and conferences, data service, project support, research visits and doctoral program. IZA engages in (i) original and internationally competitive research in all fields of labor economics, (ii) development of policy concepts, and (iii) dissemination of research results and concepts to the interested public.

IZA Discussion Papers often represent preliminary work and are circulated to encourage discussion. Citation of such a paper should account for its provisional character. A revised version may be available directly from the author. 
IZA Discussion Paper No. 5840

July 2011

\section{ABSTRACT}

\section{Preferences for Consistency ${ }^{*}$}

This paper studies how a preference for consistency can affect economic decision-making. We propose a two-period model where people have a preference for consistency because consistent behavior allows them to signal personal and intellectual strength. We then present three experiments that study main predictions and implications of the model. The first is a simple principal-agent experiment that shows that consistency is valued by others and that this value is anticipated. The second experiment underlines the crucial role of early commitment for consistency preferences. Finally we show how preferences for consistency can be used to manipulate choices.

JEL Classification: C91, D03, D64

Keywords: consistency preferences, experiments, early commitment, charitable giving, social influence

Corresponding author:

Armin Falk

University of Bonn

Adenauerallee 24

53113 Bonn

Germany

E-mail: armin.falk@uni-bonn.de

\footnotetext{
* We thank Roland Bénabou, Edward Glaeser, Uri Gneezy, Daniel Krähmer, Benny Moldovanu, Joel Sobel, Dezsö Szalay and Jean Tirole for helpful discussions. Valuable comments were also received from seminar participants at University of California - San Diego, Columbia University, Harvard University, University of Mannheim, Princeton University and Stockholm University. Financial support from the European Research Council (starting grant) is gratefully acknowledged.
} 


\section{Introduction}

The desire to be and appear consistent is a powerful determinant of human behavior. Once we have made a decision or taken a stand, we often experience pressure to live up to that commitment. In this paper, we develop a simple model that specifies motives and conditions that lead to consistent behavior. This allows predicting the role of consistency in different decision contexts. Moreover, we provide results from three experiments and a survey study that test the main predictions and implications of the model and underscore the behavioral importance of consistency preferences.

Our model is built on the notion that consistent behavior is associated with "personal and intellectual strength" (Cialdini, 1984). Evidence from social psychology suggests that while consistency signals positive personality traits, inconsistent behavior is generally associated with undesirable personal characteristics (see Asch, 1956 or Allgeier, Byrne, Brooks and Revnes, 1979). Inconsistent beliefs, words or deeds are often indicative of confusion or even mental illness. In the model decision-makers signal positive traits when acting consistently. There are two types of decision-makers who repeatedly face the same choice problem. Types with high personal and intellectual strength perfectly know their preferred outcome while types with low strength are uncertain about it. Before making a decision, low strength types receive noisy signals about their preferred outcome. Regarding behavior over time, high strength types make consistent choices. However, the beliefs, and consequently the choices, of low strength types can be inconsistent. Thus personal and intellectual strength is associated with consistent choices.

We assume that decision-makers' utility consists of two parts, a "standard" part reflecting material concerns and a reputational part capturing decision-makers' image concerns for strength. This creates a trade-off between choosing according to updated beliefs and reputational concerns. We show the existence of a Perfect Bayesian Equilibrium where decision-makers display preferences for consistency because consistent behavior allows them to signal high personal and intellectual strength. The model allows for several interpretations. The value of signaling can be interpreted as hedonic, i.e., people like it if others think positively about them, or as strategic in the sense that people expect benefits from future interactions, e.g., in the labor market. Depending on the context signaling of strength is related to ability and knowledge, identity and personality or predictability and reliability. Finally, the recipient of the signal can be others but also the decision-maker himself. In this case the decision-maker learns about her own type by observing and inferring from her own behavior (e.g., as in Bénabou and Tirole, 2004 and 
2006).

In the second part of the paper we report evidence from three decision experiments and a survey study. The first experiment tests the basic logic of our model in a simple principal-agent framework. We address two questions: do principals value consistency of agents and is this value anticipated by agents? In the experiment the decision context is a simple estimation task. Principals receive information about the estimation behavior of two agents and need to select one for an additional estimation task. We find that agents who estimate more consistently have a significantly higher chance of being selected by principals. Anticipating the value of consistency, agents' estimates in this treatment are more consistent than in a control treatment where we eliminated the strategic value of consistency.

The second experiment studies the role of early commitment for the preference for consistency. Intuitively, actively committing to an opinion, belief, intention or action is a precondition for observing consistent or inconsistent behavior. Without commitment, i.e., without taking a stand or an action, possible inconsistencies are impossible to detect. In a simple estimation context subjects have to perform an estimation task and receive valuable information regarding the solution of the task. In the main treatment, subjects commit to a first estimate prior to receiving the helpful information and without knowing that they will later receive it. After they have received this information they are free to revise their first estimate. In the control treatment, no prior commitment is made. We find that the deviation of the final estimate from the valuable information is significantly higher in the main treatment than in the control treatment. Prior commitment makes subjects neglect valuable information leading to lower payoffs.

In the third experiment we examine the role of consistency preferences as a means of social influence. The trick is to "tempt" a person to make a biased statement. In a second step she is confronted with a request related to that statement and the pressure to live up to it. Provided that the first statement involves little to no cost, it is relatively easy to provoke biased statements. The preference for consistency will make the person want to live up to the biased statement and act against her actual interest. We test this prediction in the context of pro-social decision-making. We find that pro-social behavior in the presence of biased statements systematically differs from behavior in a control treatment where no first statements were made. Finally, in our survey study we show how the preference for consistency can be used to manipulate subjects' responses on a particular matter, simply by adding an additional related question to the survey. 
Our work is related to a literature in social psychology. Cialdini (1984) summarizes much of the evidence and discusses several explanations for consistent behavior. In particular he highlights the role of consistency as a signal of positive attitudes. An alternative interpretation of consistent choices relies on the notion of cognitive dissonance. This approach basically assumes that consistent behavior reflects a desire to avoid cognitive dissonances. Early work in this direction was developed in Heider (1946), Newcomb (1953) and Festinger (1957). ${ }^{1}$ Another potential driver of consistent behavior is based on the idea that thinking is not costless. If thinking does involve cognitive costs, it may in fact be optimal to stick to a particular behavioral strategy and not to change behavior in response to new information or new signals. It is likely that these motives all play some role and often act in concert. Note, however, that neither cognitive dissonance nor cost of thinking are sufficient to explain all results of our experiments. In particular, treatment differences in our first experiment (repeated estimations with and without the presence of a principal) can be explained in terms of our model and the notion that consistency signals strength. However, neither cognitive dissonance nor cost of thinking would predict any treatment difference.

Note that our notion of consistency is conceptually different from anchoring effects. In a classical anchoring experiment, Tversky and Kahneman (1974) for example generated a random number between 0 and 100 and asked subjects if the number of African nations in the United Nations was greater than that number. Then they asked subjects to estimate the number of African nations in the United Nations. They find that the randomly generated number (the anchor) significantly affected estimates. Studies on anchoring manipulations differ from the notion of consistency in that they document effects of random unrelated numbers on subsequent choices. In our paper, subsequent choices are affected by prior actions or statements. In addition the role of reputation stressed in our model is not present in work on anchoring effects, which also implies that anchoring effects cannot explain our experimental findings.

In the economics literature Eyster (2002) and Yariv (2005) have suggested models of consistent behavior. In Eyster (2002) people have a taste for rationalizing past mistakes by taking current actions that justify these mistakes. His model offers an explanation for the well-known "sunk-cost effect". It also predicts procrastination in search contexts and overbidding in wars of attrition. Yariv (2005) proposes a model where people have a

\footnotetext{
${ }^{1}$ Akerlof and Dickens (1982) incorporate cognitive dissonance theory into an economic model. In an empirical study, Mullainathan and Washington (2009) examine the consequences of cognitive dissonance in the context of voting behavior.
} 
taste for consistency of beliefs held over time, thereby reducing cognitive dissonance. Her model can explain a variety of phenomena such as underpinnings of overconfidence and underconfidence, persistence of actions over time or why people sometimes might prefer to receive less accurate information. Different to our approach, Eyster (2002) and Yariv (2005) directly assume a taste for consistency while in our model this taste results from a desire to signal strength. Also, their models focus on internal consistency while our model stresses the role of reputation for consistency preferences. Ellingsen and Johannesson (2004) and Vanberg (2008) refer to the taste for consistency as a possible reason for why people incur costs of lying and thus keep their promises. In fact, breaking promises can be viewed as a particularly obvious form of inconsistency. On a more general level, our model belongs to a class of models where decision-makers try to signal positive traits through their actions (as for example in Bernheim, 1994, Prendergast and Stole, 1996, Bénabou and Tirole, 2006, Ellingsen and Johannesson, 2008 or Andreoni and Bernheim, 2009).

The remainder of the paper is organized as follows: In the next section we introduce our model. In section 3 we present the three experiments and our survey study. Section 4 concludes and discusses several implications of our work for, e.g., the design of committee procedures or problems of self-control.

\section{The Model}

We model the intuition that “... a high degree of consistency is normally associated with personal and intellectual strength." (Cialdini, 1984). We choose a very simple setup with two types of decision-makers who choose between two alternatives. The model formalizes the notion of preferences for consistency and delivers behavioral predictions for our experiments. ${ }^{2}$

\section{$2.1 \quad$ Set-up}

There are two periods, $t=1,2$. In both periods, a decision-maker $(D)$ chooses $x_{t}$ from a choice set $X=\{R e d, B l u e\}$ in public. $D$ has a preferred outcome $\mu \in X$. There are two different types of decision-makers. Types with high personal and intellectual strength (type $D_{H}$ ) perfectly know their preferred outcome $\mu$. Types with low personal

\footnotetext{
${ }^{2}$ We have also developed an alternative and more general version of the model with a continuous type and choice set. Insights and predictions of this model are qualitatively similar to the more parsimonious set-up. We therefore decided to use the latter. The continuous version is available on request.
} 
and intellectual strength (type $D_{L}$ ) are uncertain about their preferred outcome. Her type is $D$ 's private knowledge but is commonly known to be drawn from a distribution with probability $\alpha$ that $D$ is of type $D_{H}$ and $(1-\alpha)$ that she is of type $D_{L}$. Types with low strength and the public are holding an uninformative prior on $\mu$, i.e., $\operatorname{Pr}(\mu=\operatorname{Red})=$ $\operatorname{Pr}(\mu=B l u e)=\frac{1}{2}$. In both periods, before making a choice, $D_{L}$ privately receives a signal $m_{t}$ about $\mu$. Signals are of strength $p_{t}$, i.e., $p_{t}=\operatorname{Pr}\left(m_{t}=\operatorname{Red} \mid \mu=\operatorname{Red}\right)=$ $\operatorname{Pr}\left(m_{t}=B l u e \mid \mu=B l u e\right)$. We assume that signals are informative with $\frac{1}{2}<p_{t}<1$. We allow that the strength of signals differs between periods 1 and 2 , only requiring that $p_{2} \geq p_{1}$. Thus our setup captures situations where the quality of information $D_{L}$ receives may change over periods. The assumption that signals in period 2 are at least as strong as signals in period 1 is only made to focus on scenarios where contradicting signals lead to changes in beliefs about the preferred outcome. ${ }^{3}$

Upon receiving a signal $m_{t}, D_{L}$ updates beliefs about $\mu$ following Bayes' rule. Throughout the paper $l\left(m_{t}, m_{t-1}\right)$ denotes $D_{L}$ 's beliefs about $\mu$ in terms of the probability she assigns on Red being her preferred outcome conditional on signals $m_{t}$ and $m_{t-1}$ (if $m_{t-1}$ exists $)$, i.e., $l\left(m_{t}, m_{t-1}\right)=\operatorname{Pr}\left(\mu=\operatorname{Red} \mid m_{t}, m_{t-1}\right)$.

Since the prior on $\mu$ is uninformative, $D_{L}$ 's updated period 1 belief is determined by the signal she received in period $1, m_{1}$. Accordingly, the updated belief on $\mu$ in period 1 is $l\left(m_{1}=R e d\right)=p_{1}>\frac{1}{2}$ and $l\left(m_{1}=\right.$ Blue $)=\left(1-p_{1}\right)<\frac{1}{2}$, respectively. In period $2, D_{L}$ receives an additional signal $m_{2}$ and updates again. Thus:

$$
\begin{aligned}
& l\left(m_{2}=R e d, m_{1}=R e d\right)= \\
& \frac{p_{1} * p_{2}}{p_{1} * p_{2}+\left(1-p_{1}\right)\left(1-p_{2}\right)}>\quad \frac{1}{2} \\
& l\left(m_{2}=\text { Blue }, m_{1}=R e d\right)= \\
& \frac{p_{1} *\left(1-p_{2}\right)}{p_{1} *\left(1-p_{2}\right)+\left(1-p_{1}\right) * p_{2}} \leq \frac{1}{2} \\
& l\left(m_{2}=\text { Blue }, m_{1}=\text { Blue }\right)=\quad 1-\frac{p_{1} * p_{2}}{p_{1} * p_{2}+\left(1-p_{1}\right)\left(1-p_{2}\right)}<\quad \frac{1}{2} \\
& l\left(m_{2}=\text { Red }, m_{1}=\text { Blue }\right)=1-\frac{p_{1} *\left(1-p_{2}\right)}{p_{1} *\left(1-p_{2}\right)+\left(1-p_{1}\right) * p_{2}} \geq \quad \frac{1}{2}
\end{aligned}
$$

In both periods, the decision-maker chooses $x_{t}$ in order to maximize utility. $D$ 's utility function consists of two components. The first is "standard" outcome-based utility. Standard utility is 1 if $D$ chooses $x_{t}=\mu$ and 0 otherwise. The decision-maker also cares about her reputation. She likes it, if the public perceives her as having high personal

\footnotetext{
${ }^{3}$ If the period 2 signal is less informative than the period 1 signal, updated period 2 beliefs always remain in line with the signal from period 1 even in case of contradicting signals. Consequently types $D_{L}$ would always choose consistently anyway.
} 
and intellectual strength. An alternative interpretation of the reputational concern is a desire for a positive self-image (similar as in Bénabou and Tirole, 2004 and 2006). In this case decision-makers receive a perfect signal about their personal and intellectual strength prior to their decision. Thus, when deciding, they know their strength. However, for their self-assessment, this knowledge is not readily available, e.g., due to reasons of imperfect recall. Since actions are easier to recall than signals, decision-makers use past actions for their self-assessment. Thus the model is compatible with the intuition that people care about their self-image and construct self-image from past actions. In the following we describe the model mostly in terms of public reputation but always mean to include a self-signaling interpretation. Reputational concerns are expressed by

$$
-\beta * \operatorname{Pr}\left(\text { type }=D_{L} \mid x_{t}, x_{t-1}\right)
$$

$\operatorname{Pr}\left(\right.$ type $\left.=D_{L} \mid x_{t}, x_{t-1}\right)$ denotes the public's (or D's) belief about D's type, conditional on $D$ 's decisions in the current period $x_{t}$ and the previous period $x_{t-1}$ (if it exists). Parameter $\beta$ is assumed to be positive and specifies how much $D$ cares about her reputation. Differences in $\beta$ might reflect, e.g., the size and importance of the public or the social distance between $D$ and the public. The nature of reputational concerns could be strategic in the sense that people expect benefits in future interactions. In labor relations, e.g., signaling higher abilities may improve hiring prospects or lead to higher wages and promotion. Alternatively, $\beta$ could reflect a hedonic value of reputation. People simply enjoy being regarded as intellectually and personally strong. Depending on the context, personal and intellectual strength is associated with different personal characteristics. In task-related choices, similar solutions to similar problems signal high ability. In repeated social interactions, personal and intellectual strength, reflected by consistent behavior, signals predictability and reliability. These are important prerequisites for relationship formation and trust (see Brown, Falk and Fehr, 2004). They also help solving coordination problems. High personal and intellectual strength is also a sign of personal identity. Identity is shaped by past actions or statements. Without continuity in actions or statements, the formation of a sense of self-identity is not possible. In that sense, high personal and intellectual strength (via consistent behavior over time) is a prerequisite for strong personal identity.

Putting these two components together, in periods 1 and $2 D_{L}$ 's expected utility is given by 


$$
E\left(U_{t}\left(x_{t}\right)\right)= \begin{cases}l\left(m_{t}, m_{t-1}\right) * 1-\beta * \operatorname{Pr}\left(\text { type }=D_{L} \mid x_{t}, x_{t-1}\right) & \text { if } x_{t}=\text { Red } \\ \left(1-l\left(m_{t}, m_{t-1}\right)\right) * 1-\beta * \operatorname{Pr}\left(\text { type }=D_{L} \mid x_{t}, x_{t-1}\right) & \text { if } x_{t}=\text { Blue }\end{cases}
$$

In periods 1 and $2, D_{L}$ maximizes $E\left(U_{t}\right)$ facing a trade-off between maximizing outcome-based utility and gaining reputation. ${ }^{4}$

Note that we assume myopic, non-forward looking behavior. Decision-makers are not anticipating period 2 decisions when deciding in period 1 . This can be justified in two ways. First, we are interested in situations where future decisions are not anticipated and believe that this is quite common. Second, and more importantly, predicted behavior is actually identical if decision-makers are forward looking. The reason is that choosing according to their beliefs in period 1 is optimal not only from a standard utility perspective. It also maximizes the likelihood of consistent behavior. It is therefore not possible to improve in terms of consistency even in situations where the decision-maker anticipates future decisions.

\subsection{Equilibrium}

We now turn to equilibrium behavior. In period 1 the equilibrium we consider is straightforward. $D$ always maximizes standard utility. Types $D_{L}$ choose $x_{1}^{*}=\operatorname{Red}$ if $m_{1}=\operatorname{Red}$ and $x_{1}^{*}=$ Blue if $m_{1}=$ Blue. Types $D_{H}$ choose their preferred outcome $\mu$. Due to the uninformative prior of the public, $D$ cannot affect her image through $x_{1}$, i.e., $\operatorname{Pr}\left(\right.$ type $\left.=D_{L} \mid x_{1}=R e d\right)=\operatorname{Pr}\left(\right.$ type $=D_{L} \mid x_{1}=$ Blue $)$. Thus simply maximizing standard utility is optimal and the behavior described above constitutes a Perfect Bayesian Equilibrium. ${ }^{5}$

In period 2 there now exists a choice history $x_{1}^{*}$ and $D$ faces a possible trade-off between standard utility and reputational concerns. We characterize the equilibrium conditional on $x_{1}^{*}$. To simplify notation we consider the case where $x_{1}^{*}=R e d$ without loss of generality.

\footnotetext{
${ }^{4}$ Utility of the high types is straightforward. Suppose a type $D_{L}$ with $\mu=\operatorname{Red}$. Her utility is described by $U_{t}\left(x_{t}\right)= \begin{cases}1-\beta * \operatorname{Pr}\left(\text { type }=D_{L} \mid x_{t}, x_{t-1}\right) & \text { if } x_{t}=\text { Red } \\ 0-\beta * \operatorname{Pr}\left(\text { type }=D_{L} \mid x_{t}, x_{t-1}\right) & \text { if } x_{t}=\text { Blue. }\end{cases}$

${ }^{5} \mathrm{As}$ is common for this type of signaling models, there exist other equilibria. For example, if reputational concerns are large enough, there exists a Perfect Bayesian Equilibrium where $D$ always chooses Red (or Blue) regardless of her beliefs about $\mu$ and her type and the public holds off-equilibrium beliefs that $D$ is a low type, i.e., $\operatorname{Pr}\left(\right.$ type $=D_{L} \mid$ Blue $)=1\left(\right.$ or $\operatorname{Pr}\left(\right.$ type $\left.\left.=D_{L} \mid \operatorname{Red}\right)=1\right)$.
} 
Types $D_{H}$ who chose $R e d$ in period 1 know with certainty that their preferred outcome is Red. For types $D_{L}$ who chose Red in period 1 we need to distinguish two possibilities. In period 2 they either receive a signal $m_{2}=$ Red or $m_{2}=B l u e$. In the first case we have that $l\left(m_{2}=R e d, m_{1}=R e d\right)>\frac{1}{2}$, in the second case $l\left(m_{2}=\right.$ Blue, $\left.m_{1}=R e d\right) \leq \frac{1}{2}$. If $D$ would simply maximize standard utility, types $D_{H}$ and types $D_{L}$ with $m_{2}=R e d$ would choose $x_{2}=R e d$ whereas types $D_{L}$ with $m_{2}=$ Blue would choose $x_{2}=B l u e .{ }^{6}$ In the presence of image concerns however, $D_{L}$ types with contradicting signals face a trade-off between maximizing standard utility and signaling personal and intellectual strength. We show under which conditions there exists a Perfect Bayesian Equilibrium in period 2 where types with low strength and contradicting signals nevertheless choose consistently, thereby sacrificing expected standard utility.

In the equilibrium, types $D_{H}$, types $D_{L}$ with signals $m_{2}=R e d, m_{1}=\operatorname{Red}$ and types $D_{L}$ with signals $m_{2}=$ Blue, $m_{1}=$ Red all behave consistently choosing Red in period 2 . For this to be an equilibrium it suffices to check incentive compatibility for low strength types with contradicting signals. If incentive compatibility is fulfilled for these types it is straightforward that for types $D_{H}$ and types $D_{L}$ with signals $m_{2}=\operatorname{Red}, m_{1}=\operatorname{Red}$ it is fulfilled as well. Decision-makers $D_{L}$ with signals $m_{2}=$ Blue, $m_{1}=$ Red hold beliefs $l\left(m_{2}=\right.$ Blue, $m_{1}=$ Red $) \leq \frac{1}{2}$. We need to check that they are better off choosing Red than choosing Blue. Standard utility is $l\left(m_{2}=\right.$ Blue, $\left.m_{1}=R e d\right) * 1$ when they choose Red and $\left(1-l\left(m_{2}=\right.\right.$ Blue, $m_{1}=$ Red $\left.)\right) * 1$ when they choose Blue. Reputational utility is $-\beta * \operatorname{Pr}\left(\right.$ type $\left.=D_{L} \mid \operatorname{Red}, \operatorname{Red}\right)=-\beta *(1-\alpha)$ if they choose consistently and $-\beta * \operatorname{Pr}\left(\right.$ type $=D_{L} \mid$ Blue, Red $)=-\beta$ if they choose inconsistently. ${ }^{7}$ We end up with the following condition: $D_{L}$ 's with contradicting signals prefer Red over Blue if

$$
\alpha * \beta \geq 1-2 * l\left(m_{2}=\text { Blue }, m_{1}=\text { Red }\right) .
$$

The above condition captures the trade-off between standard utility and reputational concerns. The left hand side describes reputational gains from choosing consistently while the right hand side represents the costs in terms of standard utility. If image concerns are sufficiently high, decision-makers display a preference for consistency because consistent

\footnotetext{
${ }^{6}$ If signals in periods 1 and 2 are of equal strength, $D_{L}$ 's with contradicting signals are indifferent in terms of standard utility between Red and Blue.

${ }^{7}$ Note that we assume off-equilibrium beliefs such that the public infers low personal and intellectual strength from inconsistent behavior. We believe that this assumption is plausible. High types know their preferred outcome with certainty. Consequently they have the highest expected costs in terms of standard utility from choosing inconsistently. Also, if only a small fraction of decision-makers would not have any reputational concerns and only maximize standard utility, only low types would choose inconsistently. In addition, our equilibrium satisfies the Intuitive Criterion (Cho and Kreps, 1987).
} 
behavior allows them to signal personal and intellectual strength. Note that if reputational concerns are small, there exists an equilibrium in period 2 where $D$ always chooses to maximize standard utility. We summarize this result in the following proposition.

PROPOSITION 1: Assume w.l.g. that $x_{1}^{*}=$ Red. If reputational concerns $\beta$ are sufficiently large, i.e., $\alpha * \beta \geq 1-2 * l\left(m_{2}=\right.$ Blue, $\left.m_{1}=R e d\right)$, there exists a Perfect Bayesian Equilibrium in period 2, where $D$ always chooses $x_{2}^{*}=x_{1}^{*}=\operatorname{Red}$.

Proposition 1 states the main result of our model, namely, that decision-makers have a preference for consistent behavior. In period 2, decision-makers do not simply maximize standard outcome-based utility. Instead, they act consistently with their period 1 choice in order to signal high personal and intellectual strength. Thus, in equilibrium, they are willing to sacrifice outcome-based utility to increase their reputational utility.

\section{$3 \quad$ Experimental Evidence}

In this section we present evidence from three experiments designed to test the basic logic of the model and to examine different applications of preferences for consistency. In particular we address the following issues: First, we study the signal value of consistent behavior in the context of a simple principal agent game. In the second experiment we investigate the role of commitment. The idea is that without explicit commitment to some point of view, statement or intention, inconsistencies are impossible to detect and consequently costs of inconsistency are less important. Our third experiment demonstrates the importance of consistency preferences for social influence and manipulation. In addition, we present evidence from a study that shows how the taste for consistency can be used to manipulate survey answers. ${ }^{8}$

\subsection{Experiment 1: The Value of Consistency}

Design: The first experiment tests the central assumption of the model, that consistent behavior is valued. In the experiment the decision context involves a simple estimation task. We test whether principals infer higher ability from more consistent estimates and whether agents anticipate this.

\footnotetext{
${ }^{8}$ Instructions for the three experiments and the complete survey can be found in Appendix C.
} 
We ran two treatments. In the main treatment, upon arrival, subjects were randomly assigned to the roles of principals and agents. ${ }^{9}$ In each session there were twice as many agents as principals. Subjects were seated in separate rooms according to their roles. The experiment involved two stages. All subjects were informed about both stages at the beginning. In the first stage, agents had to perform two estimation tasks. Both tasks consisted of estimating how many times the letter "e" appeared in a text with 1,966 letters. We had selected two texts where the number of e's was identical. Both, agents and principals were informed about this. The correct number was 233. Subjects saw the first text for 60 seconds on their computer screen. Then they had 60 seconds to state their estimate about the number of e's (first estimate). Without getting any feedback on the first task, agents then saw the second text for 60 seconds. Again they had 60 seconds to provide their estimate for the second text (second estimate). Subjects were paid for accuracy. For both estimates the following rule applied: The maximum profit for each estimate was five Euro, which the agent received if her estimate was less than 1 percent above or below the correct number. For every percentage point the estimate deviated from the correct number, 10 Cents were deducted. If the estimate was more than 50 percent above or below the true value, profits were zero. Negative earnings were not possible.

After all agents had completed their two estimates, the second stage began. Two agents were randomly assigned to one principal. The decision of the principal was to select one of the two agents for a third estimation task, which was known to be similar to the first two estimation tasks. The principal was paid according to the precision of the estimate in this third task. Thus principals had an incentive to select the agent who they thought is most able in the estimation task. For their decision, principals were informed about the absolute difference between the first and the second estimate for both agents assigned to them. This information was provided on an answer sheet. ${ }^{10}$ Note that we did not display the four single estimates of the two agents. The reason is that we wanted to allow principals only the kind of inference the public can make in our model. More precisely, if we would have given principals the four single estimates, the two estimates of agent 1 would serve as a signal about the true preferences of agent 2 , given that both have the same preference $\mu$ (they want to estimate the identical number). If principals observe this signal, agents' two estimates reveal different information about D's strength than in

\footnotetext{
${ }^{9}$ In the instructions we used a neutral framing. Subjects were called "participants A" and "participants B", respectively.

${ }^{10}$ Information was provided anonymously, i.e., principals could not link information to actual subjects in the experiment.
} 
the absence of that knowledge. Therefore we decided only to provide absolute differences between estimates to the principals, thereby only allowing the kind of inference on D's strength that is assumed in our model.

On their answer sheet principals had to select "their" agent. The third task was to estimate how many times the letter "a" appears in a text of again 1966 letters. Principals were paid according to the accuracy of the selected agent's third estimate. The maximum payoff was ten Euro, which was paid if the agent's estimate was less than 1 percent above or below the correct number. For every percentage point the estimate deviated from the correct number, 20 Cents were deducted. If the estimate was more than 50 percent above or below the correct value, principal's payoff was zero. Agents had an incentive to be selected and to estimate as precise as possible in the third task. They received a prize of 10 Euro for being selected. In addition, they were paid according to accuracy identically to the payment scheme in the first two estimates.

Principals' selection decisions inform us about the potential value of estimating consistently. However, to examine whether agents anticipate this value and actually behave more consistently we need an additional treatment that eliminates (or reduces) the importance of reputational concerns for consistency. This is what we do in the control treatment. The control treatment was simply the first stage of the main treatment, i.e., agents estimate how many times the letter "e" appeared in the two texts used in the main treatment. The payoff scheme for the two tasks was identical to that of the main treatment. Comparing behavior between the two treatments informs us whether agents anticipate the value of consistency and therefore behave more consistently in the main treatment.

Procedural Details: A total of 168 subjects participated in six sessions. In the main treatment, 64 subjects participated as agents and 32 as principals. 72 subjects participated in the control treatment. Subjects were mostly students from various fields at the University of Bonn and were recruited using the online recruitment system by Greiner (2003). No subject participated in more than one session. The experiment was run using the experimental software z-Tree (Fischbacher, 2007). The principals made their choice on an answer sheet. Sessions lasted on average about 60 minutes in the main treatment and 45 minutes in the control treatment. Average earnings were 12.90 Euro for principals and 12.06 Euro for agents, including a show-up fee of eight Euro for principals and four Euro for agents. ${ }^{11}$

\footnotetext{
${ }^{11}$ One Euro was worth about 1.35 U.S. dollar at the time.
} 
Hypotheses: Principals value consistent behavior. They infer high ability from consistent estimates. Thus agents who estimate more consistently should have a higher probability of being selected by principals. In our model the value of consistency is expressed as an increase in the reputational concern $\beta$. While reputational concerns in the control treatment $\left(\beta_{c}\right)$ are not necessarily zero (e.g., due to self-signaling motives), reputational concerns in the main treatment $\left(\beta_{m}\right)$ are higher, i.e., $\beta_{m}>\beta_{c}$. This follows simply from the strategic value of reputation for high ability. In the main treatment we implemented a tournament incentive structure where agents win a prize if they outperform the other agent. These tournament incentives lead to a strategic value of behaving consistently that is not present in the control treatment. A higher $\beta$ leads to greater importance of the desire to be and appear consistent relative to the goal of maximizing standard utility. Consequently, the likelihood of an equilibrium where all decision-makers behave consistently is higher in the main treatment compared to the control treatment. Proposition 1 states the condition under which an equilibrium where all decision-makers act consistently exists: $\alpha * \beta \geq 1-2 * l\left(m_{2}=\right.$ Blue, $\left.m_{1}=R e d\right)$. It can be easily seen that an increase in $\beta$ makes the fulfillment of this condition more likely. ${ }^{12}$ Our main hypotheses can be summarized as follows:

\section{HYPOTHESIS EXPERIMENT 1: (i) The likelihood that an agent is selected by a} principal decreases in the absolute difference between first and second estimate. (ii) The absolute difference between first and second estimate is smaller in the main treatment than in the control treatment.

Results: The first result concerns the selection decisions of principals. In line with our hypothesis, a higher absolute difference between the two estimates decreases the likelihood of being selected. Figure 1 shows that the likelihood of being selected is about 70 percent for differences between zero and five and declines for larger differences. For differences larger than 31, e.g., the likelihood drops to about 22 percent. The decrease in likelihood is significant as shown by a simple Probit regression. When we regress the probability of being selected on the absolute differences between the estimates we get a negative and significant coefficient ( $\mathrm{p}$-value $<0.01$ ). The marginal effect is -0.012 , indicating that an increase in the absolute difference by one point decreases the likelihood of being selected by about 1.2 percent. Further evidence comes from the observation that

\footnotetext{
${ }^{12}$ The simplistic character of this prediction follows from the simple structure of our model. A more general version of the model makes the prediction that an increase in reputational concerns should make all decision-makers behave more consistently, leading to a shift in the distribution of distances between the two estimates. This version with a continuous type and choice set is available upon request.
} 
among all principals 75 percent select the agent with the smaller absolute difference. A simple binomial test rejects the null hypothesis that principals randomized with equal probability ( $\mathrm{p}$-value $<0.01)$.

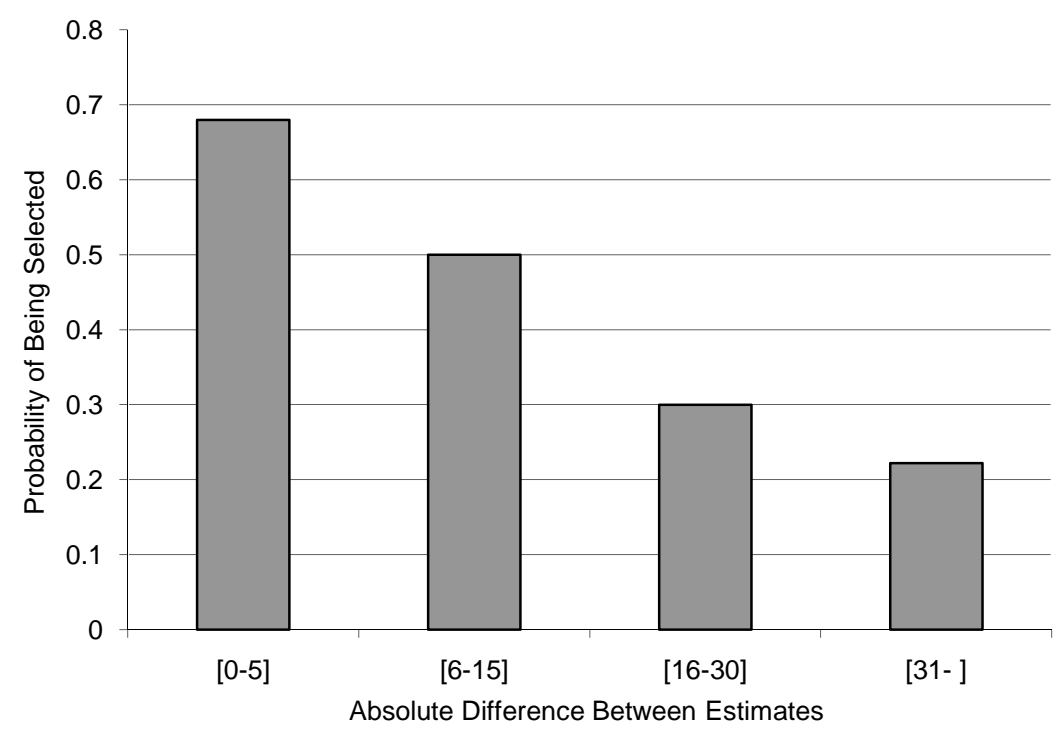

Figure 1: Probability of being selected by principal dependent on the absolute difference between two estimates.

We now turn to agents' behavior. The correct answer for both estimations was 233. Using all estimates (main and control treatment), the average first estimate was 220.57 while the average second estimate was 215.64. ${ }^{13}$ The variance in estimates was rather high. The standard deviation of all estimates in the first task was 83.29, in the second it was 74.39. At the end of the experiment, we asked agents in the control treatment to briefly describe their estimation strategy for the two estimation tasks. ${ }^{14}$ Almost all decision-makers who answered the question described a similar procedure. First they counted the number of e's for a couple of rows. Then they counted the total amount of rows in the text and projected the total number of e's in the text.

Given principals' behavior, the model predicts that agents choose more consistently in the main than in the control treatment. This is in fact what we find. Figure 2 shows scatterplots of first and second estimates. The left panel displays observations from the control treatment, the right panel from the main treatment. While estimates are correlated in both treatments, the correlation is much tighter in the main treatment, i.e., decisions are more consistent. The correlation coefficients are 0.37 in the control

\footnotetext{
${ }^{13}$ The result that the average estimate from a large population is close to the true value is also referred to as the "wisdom of the crowds" (see for example Surowiecki, 2004).

${ }^{14}$ The question we asked was the following: "Please briefly describe how you proceeded in the two estimation tasks. How did you get to your estimation results?"
} 


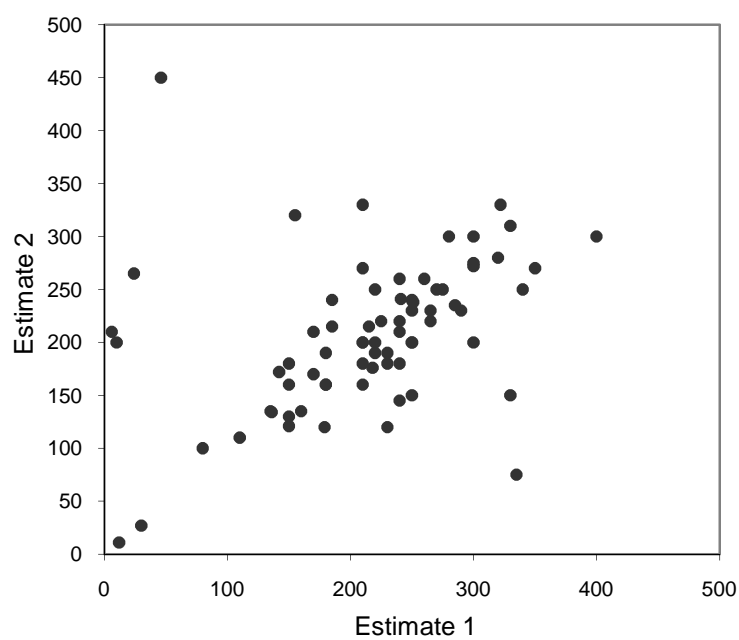

Main Treatment

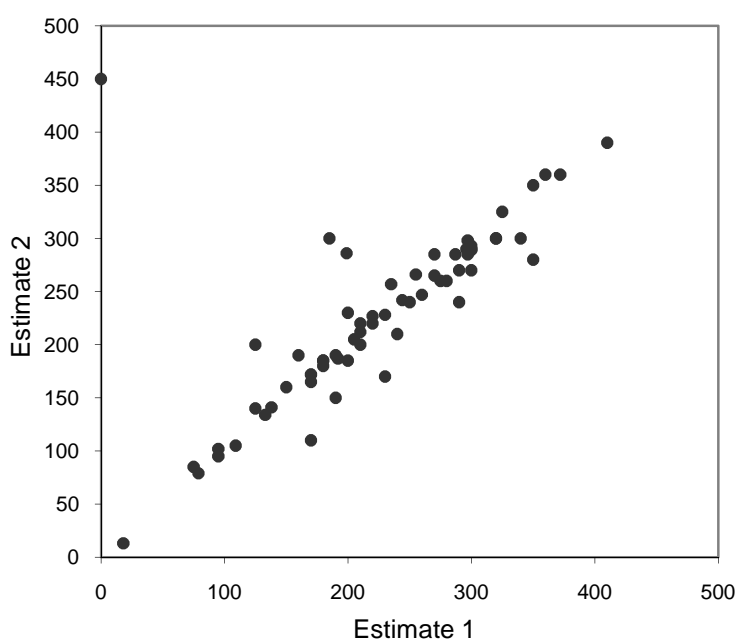

Figure 2: Scatterplots of first and second estimates for both treatments.

treatment and 0.94 in the main treatment, respectively. Figure 3 shows a histogram of absolute differences between the two estimates for both treatments. While about 70 percent of agents report an estimation difference below 15 in the main treatment, the respective number is only 25 percent in the control treatment. More than 40 percent of agents in the control treatment indicated differences larger than 30 while less than 15 percent did so in the main treatment. The average absolute difference between estimates in the control treatment is 53.8 (std. dev. 70.5) while it is only 17.3 (std. dev. 23.2) in the main treatment. This difference is significant at any conventional level (p-value $<0.0001$, using either Wilcoxon rank-sum test or simple OLS regression, regressing the absolute difference on a constant and a treatment dummy).

Our design also allows us to test whether consistent estimates are indeed a signal of estimation ability. While types with high personal and intellectual strength (in this case high estimation ability) should solve the estimation tasks very well and give consistent estimates, low strength types only receive noisy signals and therefore are likely to give inconsistent estimates. Thus, on average, more consistent agents (low absolute difference between estimates) should give better estimates. While this should hold true for the control treatment, the correlation between consistency of estimates and estimation ability might be less tight in the main treatment. The reason is that given the strategic value of consistency in the main treatment, low types should try to imitate high types by estimating consistently. In this pooling equilibrium consistency will be less informative about estimation ability compared to the control treatment. This is exactly what we find. 


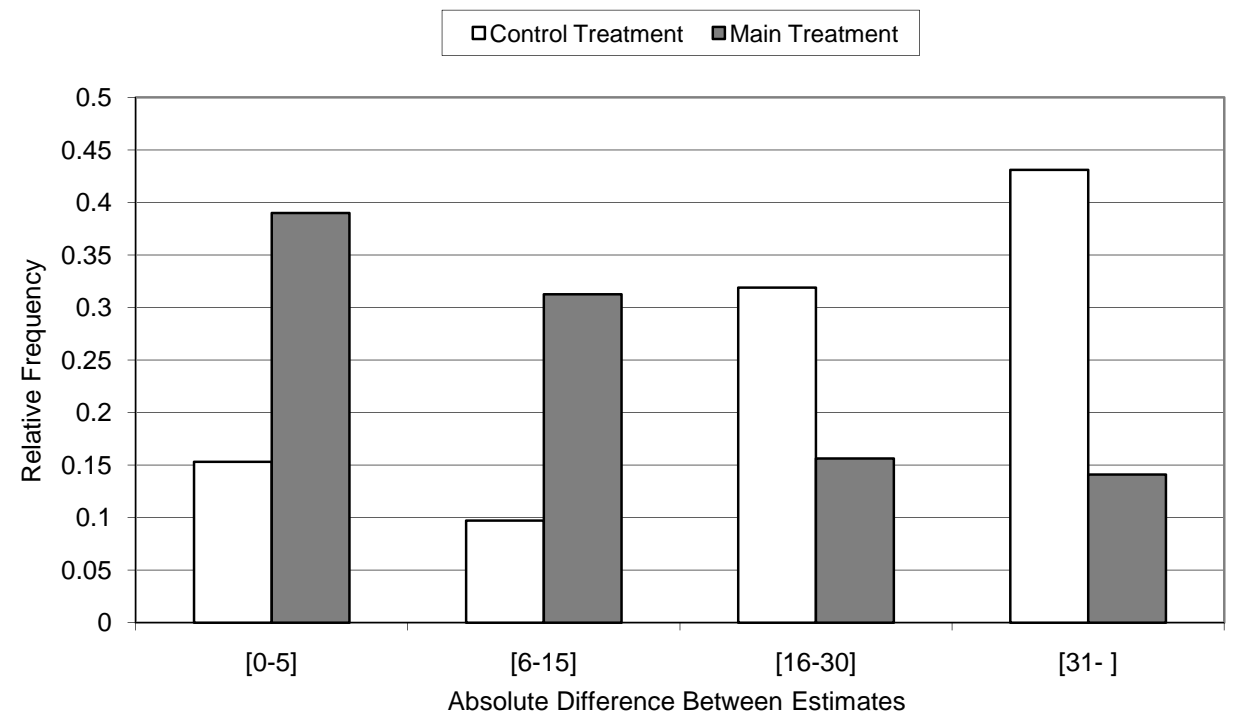

Figure 3: Relative frequency of deviations between estimates for both treatments.

In the control treatment smaller differences between estimates do reflect differences in estimation ability. More consistent agents are more able: The correlation between absolute difference in estimates and precision of estimates (measured as the sum of absolute distance between first estimate and true value and second estimate and true value) is strong and significantly positive (corr. coefficient is 0.429 , with p-value $<0.001$ )). ${ }^{15}$ Thus using the difference between the estimates as a signal of ability is generally justified. Note, however, that the informativeness of differences in estimates as a signal of estimation ability basically vanishes in the main treatment. The correlation between absolute difference in estimates and precision of estimates in the main treatment is not significantly different from zero. This suggests, in line with our model, that in the main treatment we have a pooling equilibrium where types with low personal and intellectual strength imitate types with high strength by estimating consistently. In this pooling equilibrium, consistency of estimates loses its informativeness on estimation ability. We summarize our main results as follows:

RESULT EXPERIMENT 1: The likelihood of being selected decreases in the absolute difference between the two estimates. Agents anticipate this. As a consequence, the absolute difference between first and second estimate is significantly lower in the main treatment, compared to the control treatment.

\footnotetext{
${ }^{15} \mathrm{~A}$ simple OLS regression, regressing precision of estimates on a constant and the absolute difference in estimates in the control treatment delivers the same results (coefficient of absolute difference in estimates is 0.569 , with $\mathrm{p}$-value $<0.001$ ).
} 


\subsection{Experiment 2: The Role of Commitment}

Our second experiment studies the role of early commitment. Intuitively, actively committing to an opinion, belief, intention or action is a precondition for observing consistent or inconsistent behaviors. Without commitment, i.e., without taking a stand or an action, observers will not be able to detect possible inconsistencies. Therefore, a decision-maker is not constrained by reputational concerns and can maximize utility without taking reputational costs into account. In contrast, once an individual has committed to an opinion or belief, she cannot easily change her mind without revealing some inconsistency. We test this intuition and prediction of our model in the context of an estimation task and show how commitment to an opinion can make people disregard valuable information.

Design: We study two treatments, one with commitment (main treatment) and one without (control treatment). The different steps of the experiment are illustrated in Figure 4. The main treatment is shown in the upper panel. First, subjects were explained the task: Subjects had to estimate the number of peas in a bowl. ${ }^{16}$ Subjects were paid according to the precision of their estimate. If their estimate was less than 5 percentage points above or below the true value of 3000, subjects earned 10 Euro. For every 5 percentage points the estimate deviated from the true value, we deducted 50 Cents. For example, a subject whose estimate deviated 17 percent from the true value earned 8.50 Euro. Negative earnings from the estimation task were not possible.

Subjects were seated around a table which was placed in the middle of the lab. ${ }^{17}$ After subjects had been informed about the task the bowl was shown. The bowl with peas was placed in the middle of the table. Subjects were asked to raise their hand once they had written down their estimate on an answer sheet that had been distributed at the beginning of the experiment. As soon as a subject indicated that he or she had written down an estimate, the experimenter went to the subject and recorded the subject's estimate. This means that subjects had written down their first estimate and knew that the experimenter knew this estimate. At this point, subjects had committed to their first estimate. After all subjects had stated their estimates, the experimenter announced that he would now provide subjects with additional and "helpful" information regarding the estimation task. Each subject received an information sheet containing the following sentence. "In the past it has often been the case in various estimation tasks, that the average estimate of all participants is often relatively close to the true value. The estimation task you are facing

\footnotetext{
${ }^{16} \mathrm{~A}$ picture of the bowl is shown in Appendix A.

${ }^{17}$ Subjects were seated sufficiently far away from each other, such that they could not see what other subjects were writing down.
} 
has also been conducted with a different group of participants. They have also been paid according to precision of their estimates. The average estimate of the number of peas in the bowl of this group was 2615. If you want to, you can now revise your estimate." After they received the information sheet, subjects had time to revise their estimate on their answer sheet. Of course, only the final estimate was relevant for earnings. After all subjects had indicated that they had specified their final estimate, the experimenter collected their answer sheets and the estimation task ended.

\section{Main treatment}

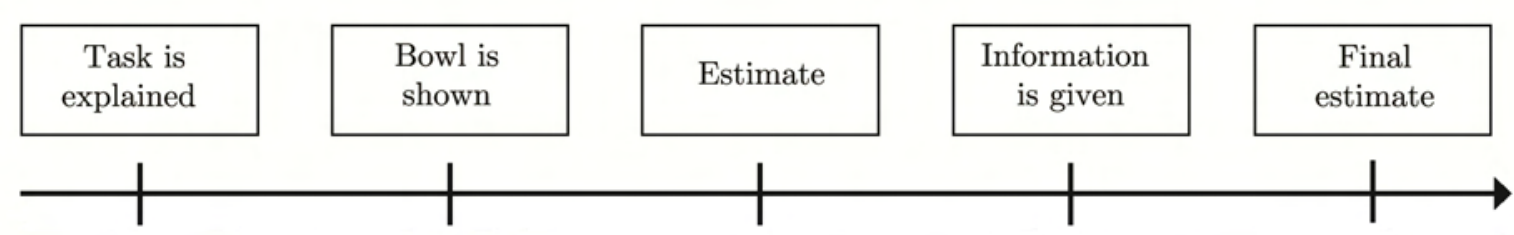

Control treatment

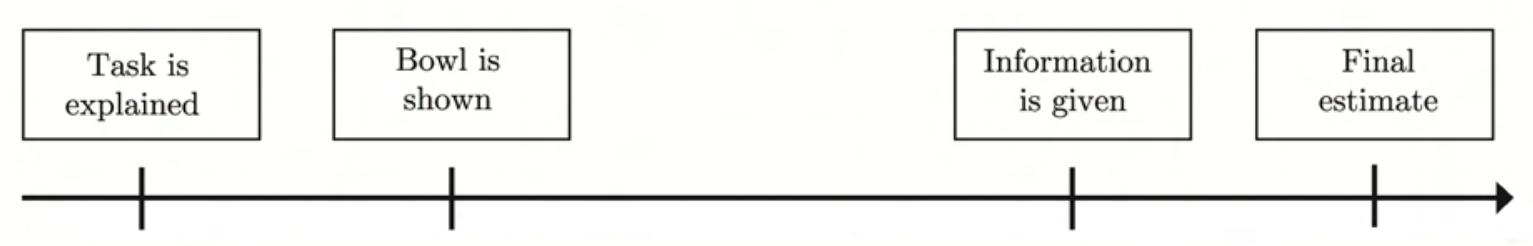

Figure 4: Timing of the experiment

The additional information we provided to subjects was based on a separate experiment we had conducted with 61 different subjects. They faced the same estimation task and were also paid according to the precision of their estimates. The average estimate of that group was 2615. In the results section we show that the additional information was in fact valuable to subjects.

Subjects in the control treatment also learned about the task and were asked to provide an estimate. The only difference between main and control treatment was that in the latter subjects did not state an estimate prior to receiving the additional information (see lower panel of Figure 4). In the control treatment, subjects saw the bowl with peas for some time prior to receiving the information sheets. ${ }^{18}$ The time was approximated to be the same as what subjects in the main treatment needed. During this time subjects could form a belief about the correct number of peas, but did not state this to the

\footnotetext{
${ }^{18}$ Note that in both treatments subjects did not know that they would receive helpful information before they actually received it.
} 
experimenter, i.e., no commitment to a first estimate was made. After subjects received the information sheets, they stated their estimate on their answer sheet. Answer sheets were collected by the experimenter and the estimation task ended.

Procedural Details: A total of 54 subjects participated in four sessions, 28 in the main and 26 in the control treatment. Subjects were mostly undergraduate students from various fields at the University of Bonn and were recruited using the online recruitment system by Greiner (2003). No subject participated in more than one session. The experiment was conducted with paper and pencil. Sessions lasted on average about 40 minutes. Subjects earned on average 12.31 Euro, including a show-up fee of 5 Euro.

Hypotheses: Here we present the intuition of our model's prediction. A formal prediction is derived in Appendix B. In both treatments subjects see the bowl and form a belief about the correct number of peas. In the main treatment subjects commit to their belief by stating it towards the experimenter. Then, in both treatments subjects receive a public signal, i.e., valuable information. In the main treatment subjects necessarily reveal inconsistency if they respond to the public signal by changing their final estimate accordingly. On the contrary, subjects in the control treatment can respond to the public signal without revealing inconsistency due to the lack of commitment to their prior belief. Therefore the preference for consistency will make subjects partially neglect the valuable information in the main treatment. Consequently final estimates in the main treatment will be further away from the public signal than in the control treatment. Since subjects in the main treatment disregard valuable information, it follows directly that the quality of estimates and therefore earnings are lower in the main than in the control treatment. ${ }^{19}$ We summarize our hypothesis as follows:

\section{HYPOTHESIS EXPERIMENT 2: The absolute difference between the final estimate} and the information value of 2615 should be higher in the main treatment, compared to the control treatment. Final estimates in the main treatment will be further away from the correct value of 3000 compared to the control treatment.

Results: Pooling data from both treatments the average (final) estimate was 2552.50. The estimation problem is very difficult and answers ranged from 500 to 5800 . Accordingly, the variance was large as indicated by a standard deviation of 1021.87. We chose

\footnotetext{
${ }^{19}$ We abstract here from self-signaling motives. Subjects could signal strength towards themselves by being consistent with their private belief. Since this motive is present in both treatments, it does not change our predictions. One might even argue that self-signaling should be stronger in the main treatment. There private beliefs might be more salient for self-evaluation because they were actually stated.
} 
a difficult task on purpose as it offers an ideal context to provide subjects with helpful information. To show that the public signal was in fact valuable we simply count the number of subjects in the main treatment whose estimate in the first estimation was closer to 3000 than 2615. It turns out that this holds for only 5 out of 28 subjects. This means that about 82 percent of subjects could improve their (first) estimate by simply choosing 2615 or by moving in this direction.

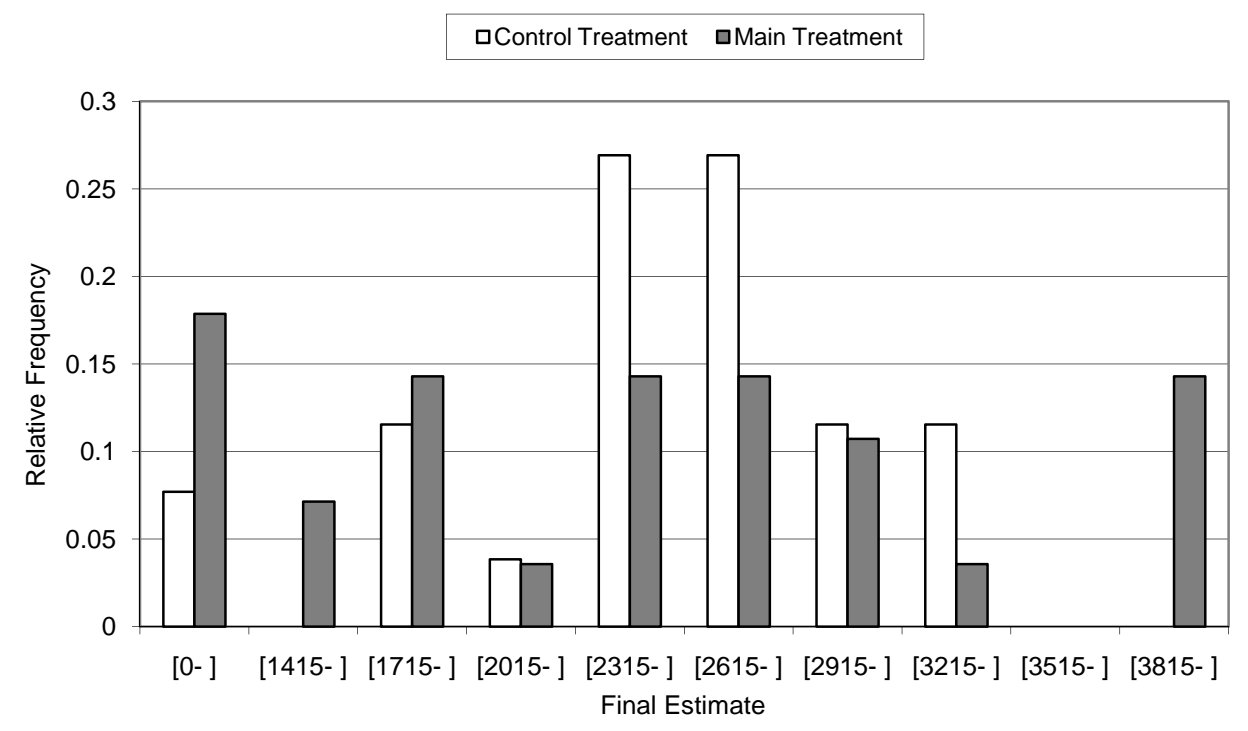

Figure 5: Relative frequency of final estimates centered around public signal (2615) for both treatments.

We now turn to our main variable of interest, the absolute deviation between final estimate and the public signal of 2615. Figure 5 shows a histogram of estimates in intervals of 300 around the information value. In the control treatment, about 54 percent of all estimates are in the interval +/-300 around the information value. In contrast only about 28 percent of all estimates in the main treatment lie within this interval. The figure also shows that extreme deviations from the public signal are more frequent in the main treatment than in the control treatment. On average, the deviation in the main treatment is 464.13 points higher than in the control treatment. The difference in deviations from the public signal is statistically significant ( $\mathrm{p}$-value $<0.07$, using Wilcoxon rank-sum test (two-sided) or simple OLS regression, regressing the absolute difference on a constant and a treatment dummy (p-value $<0.02)$ ).

Figure 6 suggests that early commitment in the main treatment affects subjects' final estimate. The figure depicts a scatterplot with subjects' first and final estimates together with a line indicating the public signal 2615. This reveals that many subjects are either at or close to the 45-degree line indicating a strong resistance to take into account new and 
valuable information. It also shows that if subjects change, they change in the direction of 2615, as predicted by the model. The correlation between first and final estimate is 0.53 ( $\mathrm{p}$-value $<0.004$ )

The disregard of the valuable public signal is associated with a decrease in the quality of estimates and earnings. On average, estimates in the main treatment are 512.46 points further away from the correct value than estimates in the control treatment. The effect is statistically significant ( $\mathrm{p}$-value $<0.03$, using Wilcoxon rank-sum test (two-sided) or simple OLS regression, regressing the deviation from the true value on a constant and a treatment dummy (p-value $<0.01)$ ).

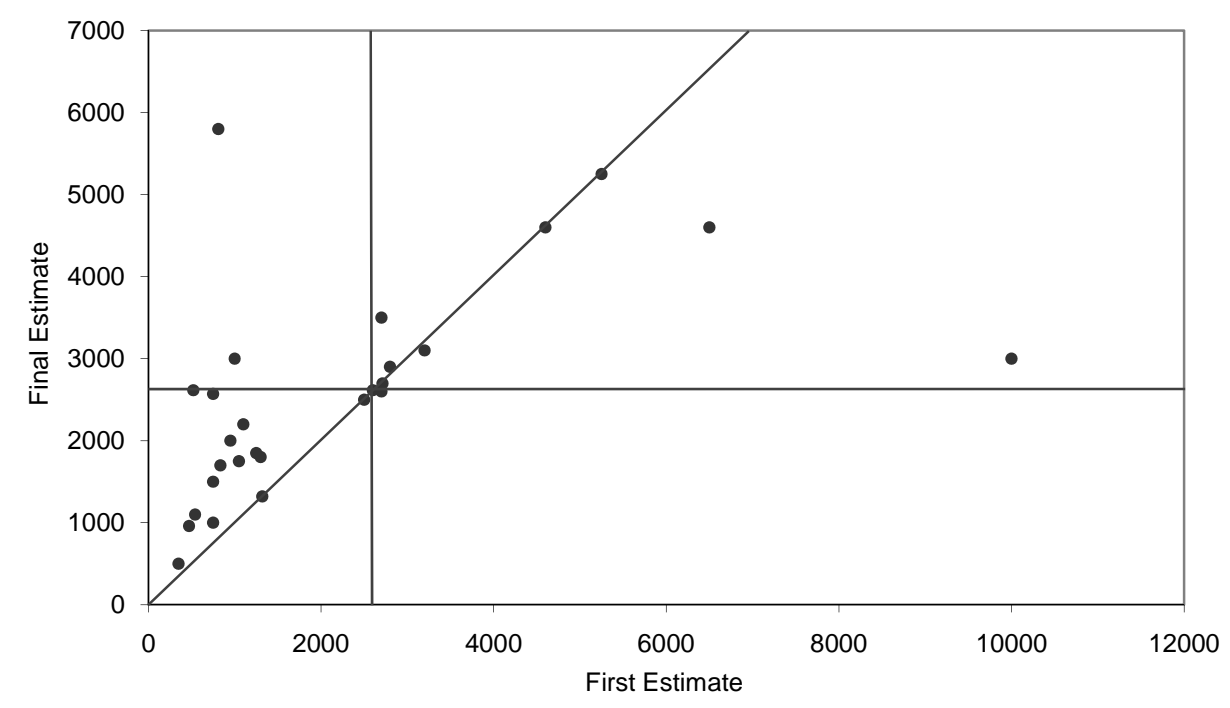

Figure 6: Scatterplot of first and final estimates in main treatment.

Note that our findings cannot be explained by subjects putting higher effort into forming a private belief in the main treatment. While given our experimental setup we believe it is plausible to assume that the quality of private signals is the same across treatments, one might argue that for some reason subjects in the main treatment try harder and thus receive better private signals. Consequently, subjects in the main treatment should also put higher weight on their private signals relative to the public signal in the Bayesian updating process. However, this does not necessarily explain that the absolute difference between final estimate and public signal is higher in the main treatment. The reason is that higher effort should make first estimates "better" and thus they should be closer to the valuable public signal to begin with, thereby reducing the deviation between final estimates and the public signal. Also, higher estimation effort would predict a higher quality of final estimates in the main treatment compared to the control treatment, which 
is exactly the opposite of what we find. We summarize our results as follows:

RESULT EXPERIMENT 2: Commitment is key: it induces subjects to act consistently at the cost of neglecting valuable information and receiving lower payoffs.

\subsection{Experiment 3: Social Influence}

In our third experiment we address the issue of social influence. The idea is that, given a preference for consistency, it is possible to influence and manipulate people's decisions. The trick is to "tempt" a person to make a biased statement. In a second step, she is confronted with a request related to that statement and the pressure to live up to it. Provoking a statement that does not necessarily reflect a person's true preferences is relatively easy if the statement involves no or only low costs. As a result the person may end up acting against her actual interest. ${ }^{20}$

Design: We study social influence in the context of prosocial decision-making. Subjects' decision is how much money to donate to a charitable fund. To study the potential of influence we conduct two treatments: In the main treatment subjects are asked how much they would donate if they were asked, prior to their donation decision. In the control treatment this question is not asked. Due to the preference for consistency, biases in prior statements ("I would donate...") might carry on to later choices because people feel obliged to act consistently with the original statement.

In both treatments, the experiment started with a survey. Subjects did not know that they would later be asked to donate money. The survey consisted of 19 sub-questions and took about 10 minutes. The survey included a short version of the so-called "Big Five" inventory and some quiz type questions. The only difference between the two treatments was that in the main treatment, we inserted one additional question in between the "Big Five" and the quiz questions. We asked subjects how they would hypothetically decide if they were asked to donate money. The question read as follows: "Imagine, in an experiment you received an amount of 15 Euro in addition to your show-up fee. You had to choose, which part of the 15 Euro you want to donate to a charitable organization. You could choose between different organizations and could donate any amount from 0 to 15. How much would you donate? Please indicate an amount between 0 and 15." In the

\footnotetext{
${ }^{20}$ In the psychology literature, this two step procedure is also known as foot-in-the-door technique. Famous examples are Freedman and Fraser (1966) and Sherman (1980) who analyze the effectiveness of the foot-in-the-door technique in different contexts, e.g., the willingness to engage in embarrassing behavior or the willingness to participate in a large consumer survey.
} 
control treatment, we removed this question from the questionnaire. After all subjects had completed the survey, the donation experiment was announced.

In the donation experiment, subjects received an endowment of 15 Euro and had to decide how much of the endowment to donate to a charity organization, and how much to keep for themselves. They could donate any amount from 0 to 15 . In case they wanted to donate a positive amount, subjects could choose their preferred charitable organizations: they could either choose from a list of 8 organizations, or could name a charity organization of their own. ${ }^{21}$

Note that the only difference between the two treatments was the hypothetical donation question. Moreover, the question was not asked right before the actual experiment but was instead embedded in a survey. The quiz questions were used to introduce some "distraction" between prior statements and donation experiment. We also did not remind subjects of their answers to the donation question when presenting the experiment. It is possible that the effects reported below would become stronger if we had either asked the question right before the experiment or reminded subjects about their answers.

Procedural Details: A total of 64 subjects participated in four sessions, 32 in the main treatment and 32 in the control treatment. Subjects were mostly undergraduate students from various fields at the University of Bonn and were recruited using the online recruitment system by Greiner (2003). No subject participated in more than one session. The experiment was conducted with paper and pencil. Sessions lasted on average about 40 minutes and subjects earned on average 13.50 Euro, including a show-up fee of 5 Euro.

Hypotheses: We hypothesized that subjects would give a biased answer when asked hypothetically how much to donate to a charitable organization. ${ }^{22}$ In fact we were expecting them to overstate their willingness to donate given that donating to charity is socially desired, and given that it was essentially costless to signal positive characteristics. Note, however, that from the viewpoint of the model it makes no difference whether they over- or understate their true willingness to donate. In the main treatment, subjects face a trade-off between acting consistently with their biased prior statement and acting according to their unbiased beliefs about their true preferences. Subjects solve this

\footnotetext{
${ }^{21}$ The list of organizations consists of very well-known and respected charities covering various targets such as helping children, fighting poverty or environmental protection. Organizations are: Brot für die Welt, Kindernothilfe, German Red Cross, Welthungerhilfe, BUND, Greenpeace, terre des hommes, Aktion Mensch.

${ }^{22}$ The model does not explain why people may give biased responses, it has to assume them. Possible reasons discussed in the literature are biases due to bounded rationality such as gambler's fallacy, base rate neglect, or hot hand fallacy (see for example Tversky and Kahneman, 1971, Grether, 1980, Charness and Levin, 2005 or Dohmen et al., 2009) or the signaling of pro-social or other motives that do not necessarily correspond to true underlying preferences (see for example Bénabou and Tirole, 2006).
} 
trade-off by choosing an actual donation level consistent with their biased statement. In the control treatment, subjects don't face such a trade-off and simply choose according to their unbiased beliefs. Therefore, actual donations in the main treatment should be higher or lower than donations in the control treatment, depending on the direction of the bias. $^{23}$

HYPOTHESIS EXPERIMENT 3: Subjects' actual donation decision in the main treatment will be biased in the direction of their hypothetical statement. As a consequence, they will donate more or less in the main than in the control treatment, depending on the direction of the bias.

Results: First we check whether subjects gave a biased hypothetical statement about their willingness to donate. To do so we compare hypothetical donations in the main treatment with actual donations in the control treatment. It turns out there is a striking bias: While average hypothetical donations are 4.27 Euro actual donations in the control treatment are 7.63 Euro. Thus actual donations in the control treatment are almost 80 percent higher (!) than hypothetical donations. This difference is statistically significant at any conventional level ( $\mathrm{p}$-value $<0.001$, Wilcoxon rank-sum test). The sign of the bias is quite surprising. A possible explanation is that in the actual donation decision we presented a list of eight charitable organizations, which may have made donations more concrete and credible, triggering a higher willingness to donate. In the hypothetical question we mentioned that subjects could choose between different charities but did not explicitly name any organizations.

Regardless of the sign of the bias, the interesting question is whether the bias carries over to the actual donation decision in the main treatment. Given that the bias is negative, the model predicts lower donations in the main compared to the control treatment. This is in fact the case. Figure 7 shows a histogram of actual donations in both treatment conditions. 38 percent of donations in the main treatment are 3 Euro or lower, the corresponding fraction in the control treatment is only about 13 percent. Likewise the fraction of donations higher or equal to 12 Euro is more than twice as high in the control compared to the main treatment. On average subjects donate 5.38 Euro in the main and 7.63 Euro in the control treatment, i.e., donations are about 42 percent lower in the main treatment than in the control condition. This difference is statistically significant using either a Wilcoxon rank-sum test ( $\mathrm{p}$-value $<0.03$, two-sided) or simple OLS regression,

\footnotetext{
${ }^{23} \mathrm{~A}$ formal prediction of our model is derived in Appendix B.
} 


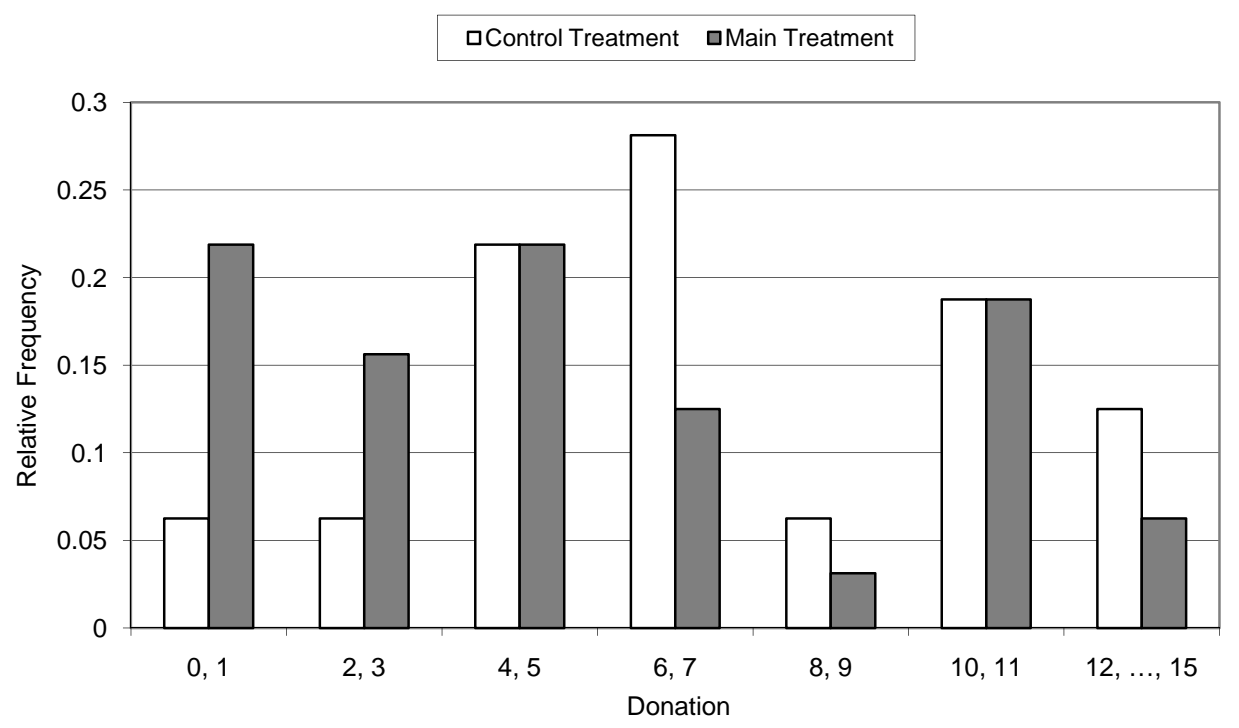

Figure 7: Relative frequency of donations for both treatments.

regressing donations on a constant and a treatment dummy (p-value $<0.02)$ ). Additional evidence for the importance of the consistency bias comes from the scatterplot shown in Figure 8. It shows that many subjects donated exactly the same amount as previously stated (almost 66 percent). The correlation coefficient between hypothetical and actual donations is 0.77 (p-value $<0.001$ ). Those subjects who deviated typically increased their donation. We summarize our results as follows:

RESULT EXPERIMENT 3: Subjects' donations are influenced by a biased hypothetical first statement. The bias is negative, resulting in lower donations in the main treatment compared to the control treatment.

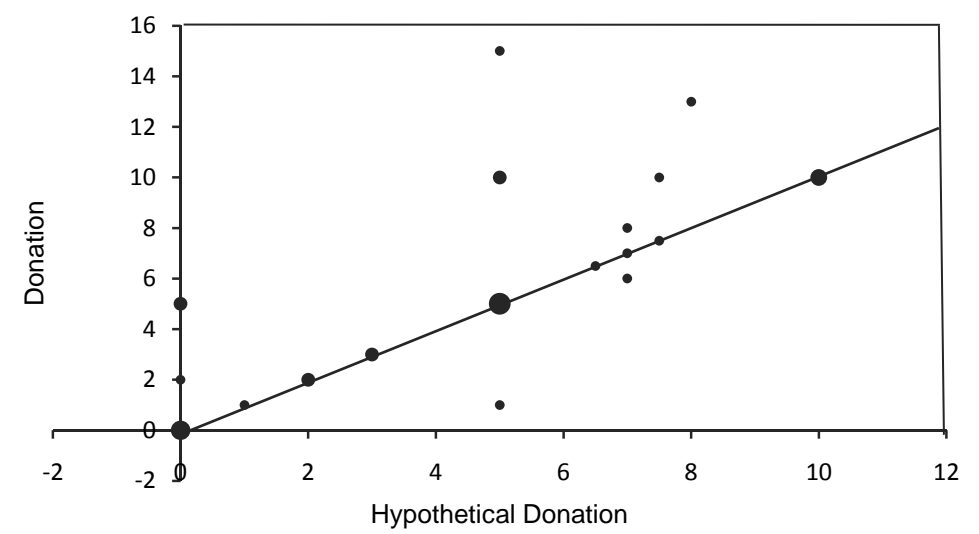

Figure 8: Scatterplot of hypothetical and actual donations in main treatment. Size of bubbles reflects number of observations. 


\subsection{Survey Manipulation}

In a simple additional study, we investigate how the design of a survey can influence and manipulate subjects' stated opinions. We designed a survey to study attitudes on how to punish a murderer. Subjects were asked to read a short text that described a horrible deed of a murderer. After reading the text subjects were asked to answer the following question: "Do you agree with the following statement? I would approve if the offender would be sent to prison for the rest of his life, never to be released." Subjects could either agree or disagree with the statement by checking the appropriate box.

We studied two treatments. In the control treatment subjects only answered the question described above. In the manipulation treatment, subjects had to answer a different but related question first, namely: "Do you agree with the following statement? Everybody deserves a second chance in life. Even dangerous criminals should be released after their imprisonment and be given a chance to start a new life." Subjects could either agree or disagree. Once subjects had answered the question, the answer sheets were collected and the question on how to punish the murderer was distributed.

We expected that most subjects in the control group would agree with the statement that the murderer should be imprisoned forever. We also expected that many subjects in the manipulation group would agree with the statement that everybody deserves a second chance. Therefore we hypothesized that subjects in the manipulation group would feel the desire to be consistent with their first answer and therefore agree less frequently with the statement that the murderer should be imprisoned forever, as compared to the control treatment. ${ }^{24}$ The study was conducted with students from the University of Bonn. 95 subjects participated, 48 in the control treatment, 47 in the manipulation treatment.

We first look at how many subjects in the control treatment agreed that the murderer should be sent to prison for the rest of his life. It turns out that 44 out of 48 subjects (91.7 percent) responded with "I agree". Then we examine how many subjects in the manipulation treatment agreed to the statement that everybody deserves a second chance in life. 26 out of 47 subjects (55.3 percent) responded with "I agree".

Given these results, we predict that in order to be consistent with the statement that everybody deserves a second chance, fewer subjects in the manipulation treatment agree to imprison the murderer forever. This is indeed what we find. Only 32 out of 47 subjects (68.0 percent) stated that they would approve if the offender would never live in freedom again. Thus the approval rate dropped from 91.7 percent in the control treatment to

\footnotetext{
${ }^{24}$ In terms of our model the problem is similar to the one studied section 3.3.
} 
68.0 percent in the manipulation treatment. This difference is statistically significant using either a Fisher exact test (p-value < 0.005) or simple Probit regression, regressing a dummy variable for "agree" or "disagree" on a constant and a treatment dummy $(\mathrm{p}$-value $<0.005)$. To summarize, we were able to significantly manipulate reported attitudes towards the punishment of a murderer simply by including an additional question. Together with the previous experimental results, our findings suggest that the preference for consistency can be used to manipulate behavior and stated preferences in a powerful and systematic way.

\section{Concluding Remarks}

We presented a model that conceptualizes the preference for consistency and allows the analysis of how it affects economic behavior. In the model, people have a preference for consistency, because consistent behavior allows them to signal strength. We conducted three experiments and a survey study that support main predictions and implications of our model. In the context of an estimation task, the first experiment shows that consistent behavior is valued as a signal of ability. Agents anticipate this and make more consistent estimates compared to a control treatment without principals, i.e., in a situation where signaling ability has no strategic value. The second experiment shows that explicit commitment is crucial for explaining preferences for consistency as commitment is a prerequisite for detecting inconsistencies. In the experiment such a commitment leads to a neglect of valuable information. The third experiment and the survey study both demonstrate the effectiveness of the preference of consistency as a means of social influence.

In our model we highlight the role of signaling positive traits as a key driver of consistent behavior. Other motives that have been discussed in the literature are reduction of cognitive dissonance and costs of thinking (see work cited in Cialdini, 1984). The most important difference between a signaling argument and fixed costs or cognitive dissonance concerns the role of third parties. We believe that the presence of observers creates a particularly strong desire to appear consistent. Moreover, our first experiment demonstrates that cognitive dissonance or cost of thinking alone are not sufficient to understand consistent behavior. While we cannot rule out that these two motives play a role as well, they cannot explain observed treatment differences. This follows simply from the fact that both motives can be relevant in both treatments. It is also unclear how cognitive 
dissonance theory or costs of thinking can explain results from our second experiment. If, as we assume, subjects form a belief about the correct estimate in both treatments, the desire to avoid cognitive dissonance (by not following the public signal) should not differ between the treatments. Also, from a cost of thinking perspective there should be no treatment difference in final estimates.

Notice that we consider situations where decision-makers face the same choice problems repeatedly and where the preferred outcome, $\mu$, remains constant over time. In this situation, personal and intellectual strength is reflected by consistent behavior. A good example is decision-making related to personality or identity. The latter is not constantly changing but remains relatively stable over long periods of time. Therefore, a person signals a strong personality by acting consistently. In changing environments where it is commonly known that the preferred outcome changes, however, personal and intellectual strength could mean to adjust quickly to new environments. In fact sticking to previous points of view could be considered rigid or even stupid. For example, if subjects in our first or second experiment would have been told that the number of letters or peas, respectively, is (very) different between the two estimations, choosing identical estimates would not signal high ability but quite the opposite. Put differently, if the circumstances that lead to a first decision have clearly changed before a second decision is taken, it is not a sign of strength to stick to the first period's choice. In this case decision-makers will, due to reasons of consistency, make sure that the public knows that circumstances have in fact changed. This explains why decision-makers (such as politicians) exert much rhetoric effort to explain the reasons for why they have changed their mind and why acting differently should not be interpreted as inconsistent behavior.

We conclude by highlighting economic implications that could be studied in future work. The preference for consistency makes people act against their immediate material interest. Early statements or choices have consequences for subsequent behavior. For instance we show that early statements on a matter can make people ignore valuable information. This is of interest for the design of committee or jury procedures. Institutionally requested commitments on a certain opinion or intention at an intermediate stage can decrease the quality of final choices as these potentially do not reflect the full level of available information. In the context of negotiations where full details of the negotiation are only sequentially revealed, statements of requests at an early stage of negotiations can increase the likelihood of negotiation failures. In the final stage of negotiations, when all information is revealed, negotiation outcomes below these requests cannot be reached 
without one party revealing inconsistency with early statements. This may be one reason why early requests are often formulated rather vaguely as this makes possible inconsistencies between requests and negotiation outcomes harder to detect. On the other hand, in many bargaining situations early requests can be used strategically to increase bargaining power. Take a simple ultimatum game situation where the responder can state a minimum acceptable offer towards the proposer in the beginning. In principle this statement is cheap-talk and should not affect the outcome of the game. Thus, in the actual game the responder should nonetheless accept any positive amount and the proposer will offer the lowest possible amount. In the presence of a desire for consistency, however, the stated minimum acceptable offer serves as a credible commitment that the responder will reject any offer below that because otherwise he would reveal inconsistency. Anticipating this, the proposer may have to offer something close to the demanded minimum. Note that the credibility of the minimum acceptable offer depends on the reputational costs from inconsistency. Consequently, early requests made in public, e.g., in front of large audience have a higher credibility than requests that are only stated towards the other bargaining party.

The desire to be consistent with stated intentions can also be a powerful means to circumvent problems of self-control. Consider smoking: A public announcement "I will stop smoking!" creates a pressure to live up to that announcement. Continuing to smoke is only possible at the cost of revealing some inconsistency, thereby signaling low personal strength. Thus, explicit public commitments can be very effective in solving problems of self-control. In fact, one reason for the effectiveness of self-help groups could be that they "force" members to publicly announce their intentions.

Our results are also informative from a methodological point of view. When designing surveys and experiments, our studies suggest interdependencies between behavior in related experiments conducted in one session, between behavior in repeated interactions or within-subjects designs, between experimental behavior and related questionnaire answers or between different survey answers. Depending on the context of the experiment or the survey study, the preference for consistency introduces a bias in behavior that potentially confounds results. 


\section{REFERENCES}

Akerlof, George and William Dickens. 1982. "The Economic Consequences of Cognitive Dissonance." American Economic Review, 72(3): 307-319.

Allgeier, A.R., Donn Byrne, Barbara Brooks and Diane Revnes. 1979. "The Waffle Phenomenon: Negative Evaluations of Those Who Shift Attitudinally." Journal of Applied Social Psychology, 9(2): 170-182.

Andreoni, James and Douglas Bernheim. 2009. "Social Image and the 50-50 Norm: A Theoretical and Experimental Analysis of Audience Effects." Econometrica, $7(5):$ 1607-1636.

Asch, Solomon. 1956. "Studies of Independence and Conformity: A Minority of One Against a Unanimous Majority." Psychological Monographs, 70 (Whole no. 416).

Bénabou, Roland and Jean Tirole. 2004. "Willpower and Personal Rules." Journal of Political Economy, 112(4): 848-886.

Bénabou, Roland and Jean Tirole. 2006. "Incentives and Prosocial Behavior." American Economic Review, 96(5): 1652-1678.

Bernheim, Douglas. 1994. "A Theory of Conformity.", Journal of Political Economy, 102(5): 841-877.

Brown, Martin, Armin Falk and Ernst Fehr. 2004. "Relational Contracts and the Nature of Market Interactions.", Econometrica, 72(3): 747-780.

Charness, Gary and Dan Levin. 2005. "When Optimal Choices Feel Wrong: A Laboratory Study of Bayesian Updating, Complexity and Affect.", American Economic Review, 95(4): 1300-1309.

Cho, In-Koo and David Kreps. 1987. "Signaling Games and Stable Equilibria." Quarterly Journal of Economics, 102(2): 179-221.

Cialdini, Robert. 1984. "Influence, the Psychology of Persuasion." New York: Harper Collins.

Dohmen, Thomas, Armin Falk, David Huffman, Felix Marklein and Uwe Sunde. 2009. "Biased Probability Judgment: Evidence of Incidence and Relationship to Economic Outcomes from a Representative Sample." Journal of Economic Behavior and Organization, 72(3), 903-915. 
Ellingsen, Tore and Magnus Johannesson. 2004. "Promises, Threats and Fairness.", The Economic Journal, 114(April): 397-420.

Ellingsen, Tore and Magnus Johannesson. 2008. "Pride and Prejudice: The Human Side of Incentive Theory." American Economic Review, 98(3): 990-1008.

Eyster, Erik. 2002. "Rationalizing the Past: a Taste for Consistency." working paper. Festinger, Leon. 1957. "A Theory of Cognitive Dissonance." Stanford, CA: Stanford University Press.

Fischbacher, Urs. 2007. "z-Tree: Zurich Toolbox for Ready-made Economic Experiments." Experimental Economics, 10(2): 171-178.

Freedman, Jonathan and Scott Fraser. 1966. "Compliance Without Pressure: The Foot in the Door Technique." Journal of Personality and Social Psychology, 4(2): 195202.

Greiner, Ben. 2003. "An Online Recruitment System for Economic Experiments." In Forschung und wissenschaftliches Rechnen 2003. GWDG Bericht 63, ed Kurt Kremer and Volker Macho, pp. 79-93. Goettingen: Ges. fuer Wiss. Datenverarbeitung.

Grether, David. 1980. "Bayes Rule as a Descriptive Model: The Representativeness Heuristic." Quarterly Journal of Economics, 95(3): 537-557.

Heider, Fritz. 1946. "Attitudes and Cognitive Organization." Journal of Psychology, 21: $107-112$.

Mullainathan, Sendhil and Ebonya Washington. 2009. "Sticking with Your Vote: Cognitive Dissonance and Political Attitudes." American Economic Journal: Applied Economics, 1 (1): 86-111.

Newcomb, Theodore. 1953. "An Approach to the Study of Communicative Acts." Psychological Review, 60: 393-404.

Prendergast, Canice and Lars Stole. 1996. "Impetuous Youngsters and Jaded OldTimers: Acquiring a Reputation for Learning." Journal of Political Economy, 104 (6): 1105-1134.

Sherman, Steven. 1980. "On the Self-Erasing Nature of Errors of Prediction." Journal of Personality and Social Psychology, 39(2): 211-221.

Surowiecki, James. 2004. "The Wisdom of Crowds." New York: Random House.

Tversky, Amos and Daniel Kahneman. 1971. "Belief in the Law of Small Numbers." Psychological Bulletin, 2: 105-110. 
Tversky, Amos and Daniel Kahneman. 1974. "Judgment under Uncertainty: Heuristics and Biases." Science, 185: 1124-1131.

Vanberg, Christoph. 2008. "Why Do People Keep Their Promises? An Experimental Test of Two Explanations." Econometrica, 76(6): 1467-1480.

Yariv, Leeat. 2005. "I'll See it When I Believe it - A Simple Model of Cognitive Consistency." working paper. 


\section{Appendix A}

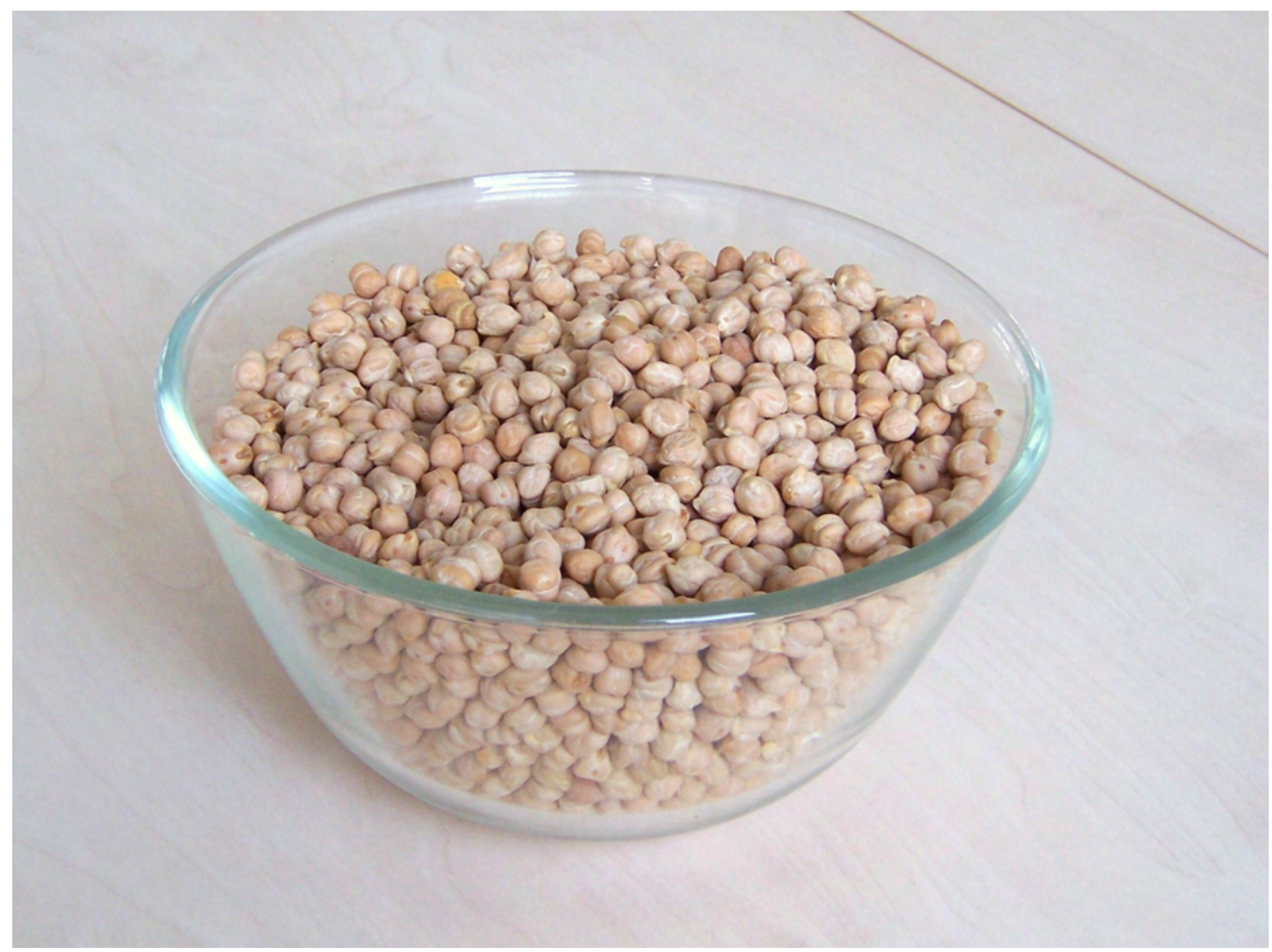

Picture of bowl with peas: This bowl was shown to subjects in the estimation task of experiment 2 . 


\section{Appendix B}

Here we derive formal predictions of our model for experiments 2 and 3.

\section{Prediction Experiment 2}

In both treatments subjects with low personal and intellectual strength (types $D_{L}$ ) receive a private signal $m_{1}$ and a public signal (the valuable information) $m_{2}^{p}$ and subjects with high personal and intellectual strength (types $D_{H}$ ) perfectly learn the true outcome. ${ }^{25}$ We assume that the public signal is of greater strength, i.e., $p_{2}^{p}>p_{1}$ and without loss of generality that $m_{2}^{p}=$ Blue. In the main treatment, low strength subjects commit to their private signal, i.e., $x_{1}=m_{1}$ and high strength subjects commit to the choice they know with certainty to be true.

For subject's final choices we proceed in two steps. First we consider an equilibrium where low strength subjects do not respond to the public signal. We show that in the main treatment, if reputational concerns are large enough, there exists an equilibrium where low strength subjects do not respond to the public signal whereas in the control treatment such an equilibrium does not exist. We then consider the equilibrium where decision-makers fully respond to the public signal. We derive conditions for existence of this type of equilibrium and show that these conditions are either more likely or impossible to be fulfilled in the control treatment than in the main treatment.

First consider the equilibrium where D does not respond to the public signal. In the main treatment this equilibrium is characterized as follows. High strength types will choose the outcome they know to be true, both in the first decision and the final decision. Low strength types will first choose following their private signal $m_{1}$, i.e., some will choose $x_{1}=$ Red and some $x_{1}=$ Blue. Final decisions of the low types will all be consistent, i.e., $D_{L}$ 's who chose $x_{1}=$ Red will choose $x_{2}=$ Red, neglecting the public signal. For this to be an equilibrium it suffices to check incentive compatibility for low strength types who received a private signal $m_{1}=$ Red. Costs in terms of standard utility from choosing Red over Blue are $1-2 l\left(m_{2}^{p}=\right.$ Blue, $m_{1}=$ Red $)$. Reputational gains are $\beta \frac{\alpha\left(1-p_{2}^{p}\right)}{\alpha\left(1-p_{2}^{p}\right)+(1-\alpha)\left(1-p_{2}^{p}\right) p_{1}+(1-\alpha) p_{2}^{p}\left(1-p_{1}\right)}$, since the public infers that the decision-maker is a low type if she chooses inconsistently, i.e., $\operatorname{Pr}\left(\right.$ type $=D_{L} \mid$ Blue, Red $)=1$ and that $\operatorname{Pr}\left(\right.$ type $=D_{L} \mid$ Red, Red $)=\frac{(1-\alpha)\left(1-p_{2}^{p}\right) p_{1}+(1-\alpha) p_{2}^{p}\left(1-p_{1}\right)}{\alpha\left(1-p_{2}^{p}\right)+(1-\alpha)\left(1-p_{2}^{p}\right) p_{1}+(1-\alpha) p_{2}^{p}\left(1-p_{1}\right)} \cdot{ }^{26}$ Thus, if the following

\footnotetext{
${ }^{25}$ Types with high personal and intellectual strength of course also receive the public signal, but do not need to respond to it since they already know the correct answer with certainty.

${ }^{26}$ In line with the baseline model we assume off-equilibrium beliefs to be such that the public infers
} 
condition is fulfilled, there exists a Perfect Bayesian Equilibrium in the main treatment where subjects do not respond to the valuable public signal.

$$
\beta \frac{\alpha\left(1-p_{2}^{p}\right)}{\alpha\left(1-p_{2}^{p}\right)+(1-\alpha)\left(1-p_{2}^{p}\right) p_{1}+(1-\alpha) p_{2}^{p}\left(1-p_{1}\right)} \geq 1-2 * l\left(m_{2}^{p}=\text { Blue, } m_{1}=\text { Red }\right)
$$

In the control treatment this equilibrium is characterized by high types choosing the outcome they know to be true, low types who received a private signal $m_{1}=R e d$ choosing $x=\operatorname{Red}$ (thereby ignoring the public signal) and low types who received a private signal $m_{1}=$ Blue choosing $x=$ Blue. For this to be an equilibrium we again check incentive compatibility for low types who received a private signal $m_{1}=R e d .^{27}$ Their costs in terms of standard utility from choosing Blue are identical to above, i.e., $1-2 l\left(m_{2}^{p}=\right.$ Blue, $\left.m_{1}=R e d\right)$. The reputational gains differ, however. Without commitment, the public cannot infer that $\mathrm{D}$ is a low type from $x=B l u e$. Instead we have that $\operatorname{Pr}\left(\right.$ type $=D_{L} \mid$ Blue $\left.)=\frac{(1-\alpha) p_{2}^{p} * p_{1}+(1-\alpha)\left(1-p_{2}^{p}\right)\left(1-p_{1}\right)}{\alpha * p_{2}^{p}+(1-\alpha) p_{2}^{p} * p_{1}+(1-\alpha)\left(1-p_{2}^{p}\right)\left(1-p_{1}\right)}\right)$. Therefore reputational gains from choosing Red are smaller and amount to $\beta\left(\frac{\alpha\left(1-p_{2}^{p}\right)}{\alpha\left(1-p_{2}^{p}\right)+(1-\alpha)\left(1-p_{2}^{p}\right) p_{1}+(1-\alpha) p_{2}^{p}\left(1-p_{1}\right)}-\right.$ $\left.\frac{\alpha * p_{2}^{p}}{\alpha * p_{2}^{p}+(1-\alpha) p_{2}^{p} * p_{1}+(1-\alpha)\left(1-p_{2}^{p}\right)\left(1-p_{1}\right)}\right)$. Since costs in terms of standard utility are positive, positive reputational gains are a prerequisite for existence of this equilibrium. However, simplification of the inequality $\beta\left(\frac{\alpha\left(1-p_{2}^{p}\right)}{\alpha\left(1-p_{2}^{p}\right)+(1-\alpha)\left(1-p_{2}^{p}\right) p_{1}+(1-\alpha) p_{2}^{p}\left(1-p_{1}\right)}-\right.$ $\left.\frac{\alpha * p_{2}^{p}}{\alpha * p_{2}^{p}+(1-\alpha) p_{2}^{p} * p_{1}+(1-\alpha)\left(1-p_{2}^{p}\right)\left(1-p_{1}\right)}\right) \geq 0$ yields $1-p_{2}^{p} \geq p_{2}^{p}$, which is impossible to be fulfilled since $p_{2}^{p}>\frac{1}{2}$.

Thus, in the main treatment, if reputational concerns are large enough, there exists a Perfect Bayesian Equilibrium where types $D_{L}$ who received a signal $m_{1}=R e d$ choose consistently and thereby ignore the public signal. This type of equilibrium does not exist in the control treatment. Intuitively, in the main treatment low types who receive a private signal $m_{1}=$ Red can only respond to the public signal by fully revealing that they are a low type while low types in the control treatment face lower reputational costs since they can "hide" behind the high types that are choosing Blue.

Now consider the equilibrium where the public signal is fully taken into account. In the main treatment this equilibrium is characterized as follows. High strength types will choose the outcome they know to be true, both in the first and in the final decision.

\footnotetext{
low personal and intellectual strength from inconsistent behavior.

${ }^{27}$ Note that here we also need to check incentive compatibility for low types that received a private signal $m_{1}=$ Blue and high types who know the true outcome to be Blue. For our purposes however it is sufficient to realize that these conditions only make the existence of this type of equilibrium in the control treatment even less likely.
} 
Low strength types will take a first decision following their private signal $m_{1}$, i.e., some will choose $x_{1}=$ Red and some $x_{1}=$ Blue. Since the public signal $m_{2}^{p}=$ Blue is more informative than the private signal, all low strength types will take the final decision $x_{2}=$ Blue, taking the public signal fully into account. Thus, the low strength types who received as private signal $m_{1}=$ Red will behave inconsistently. For this to be an equilibrium it suffices to check incentive compatibility for low strength types who received as private signal $m_{1}=\operatorname{Red} .^{28}$ Their reputational cost from choosing Blue over Red is $\beta$, since the public infers that the decision-maker is a high type if she chooses $x_{1}=x_{2}=R e d$, i.e., $\operatorname{Pr}\left(\right.$ type $=D_{L} \mid$ Red,$\left.R e d\right)=0$ and that the decision-maker is a low type if she chooses $x_{1}=$ Red and $x_{2}=$ Blue, i.e., $\operatorname{Pr}\left(\right.$ type $=D_{L} \mid$ Blue, Red $)=1$. Gains in term of standard utility from choosing Blue over Red are $1-2 l\left(m_{2}^{p}=B l u e, m_{1}=R e d\right)$. Thus, if the following condition is fulfilled, there exists a Perfect Bayesian Equilibrium in the main treatment where subjects take the public signal fully into account.

$$
\beta \leq 1-2 * l\left(m_{2}^{p}=\text { Blue, } m_{1}=\text { Red }\right)
$$

In the control treatment where subjects only take one decision this equilibrium is characterized by high types choosing the outcome they know to be true and low types choosing $x=$ Blue regardless of their private signal $m_{1}$. For this to be an equilibrium it again suffices to check incentive compatibility for low types who received a private signal $m_{1}=$ Red. Their gains in terms of standard utility from choosing Blue are identical to above, i.e., $1-2 l\left(m_{2}^{p}=\right.$ Blue, $\left.m_{1}=R e d\right)$. The reputational costs, however, differ. While the public infers a high type from $x=\operatorname{Red}$, i.e., $\operatorname{Pr}\left(\right.$ type $\left.=D_{L} \mid \operatorname{Red}\right)=0$, it cannot infer that $\mathrm{D}$ is a low type from $x=$ Blue. Instead we have that $\operatorname{Pr}\left(\right.$ type $=D_{L} \mid$ Blue $)=$ $\frac{1-\alpha}{(1-\alpha)+p_{2}^{p} * \alpha}$. We end up with the following condition for existence of a Perfect Bayesian Equilibrium in the control treatment where subjects take the public signal fully into account.

$$
\beta\left(1-\frac{p_{2}^{p} * \alpha}{(1-\alpha)+p_{2}^{p} * \alpha}\right) \leq 1-2 * l\left(m_{2}^{p}=\text { Blue, } m_{1}=\text { Red }\right) .
$$

Comparing equilibrium conditions for both treatments, one can easily see that the condition in the control treatment is easier to be fulfilled since $1-\frac{p_{2}^{p} * \alpha}{(1-\alpha)+p_{2}^{p} * \alpha}<1$. Thus, an equilibrium where information is fully taken into account is less likely in the main treatment than in the control treatment.

\footnotetext{
${ }^{28}$ For a full characterization of the equilibrium we also need to specify off-equilibrium beliefs. Again we assume that the public infers low strength from choices $x_{1}=B l u e, x_{2}=R e d$.
} 


\section{Prediction Experiment 3}

Suppose a bias in the hypothetical choice in period 1. In the language of our model, assume for example a low strength subject chooses Red in period 1 although she received a signal $m_{1}=$ Blue. Suppose the subject receives signal $m_{2}=$ Blue in period $2 .{ }^{29}$ To focus on the role of the preference for consistency as a device for social influence, we assume that subjects use the correct signal $m_{1}=$ Blue for Bayesian updating in period 2, i.e., $l\left(m_{2}, m_{1}\right)=l\left(m_{2}=\right.$ Blue, $m_{1}=$ Blue $) .{ }^{30}$ In period 2 , the actual decision, the subject maximizes expected utility:

$$
E\left(U_{2}\left(x_{2}\right)\right)= \begin{cases}l\left(m_{2}, m_{1}\right) * 1-\beta\left(\operatorname{Pr}\left(\text { type }=D_{L} \mid x_{2}, x_{1}\right)\right) & \text { if } x_{2}=\text { Red } \\ \left(1-l\left(m_{2}, m_{1}\right)\right) * 1-\beta\left(\operatorname{Pr}\left(\text { type }=D_{L} \mid x_{2}, x_{1}\right)\right) & \text { if } x_{2}=\text { Blue }\end{cases}
$$

In the equilibrium described in Proposition 1 , she will choose $x_{2}=\operatorname{Red}$ in order to be consistent with her biased period 1 statement. $^{31}$

In the control treatment subjects only take one unbiased choice $x$. Subjects receive a signal $m$ and choose $x=m$. It immediately follows that a systematic bias in the hypothetical statements of the main treatment will carry over to actual period 2 behavior. Consequently actual behavior will differ between the main and the control treatment.

\footnotetext{
${ }^{29}$ This case is particularly interesting because without a bias in period 1 , subjects who receive signals $m_{1}=m_{2}=$ Blue would consistently choose $x_{1}=x_{2}=$ Blue in equilibrium.

${ }^{30}$ If subjects would use a biased belief this would contribute to an additional bias in subjects' period 2 choice. Thus, if subjects are unaware of the bias the treatment effect would become even larger.

${ }^{31}$ Note that for $x_{2}=R e d$ to be optimal for the subject, the condition is different from the one stated in Proposition 1. The reason is that a subject with signals $m_{1}=m_{2}=$ Blue has higher costs (in terms of standard utility) from choosing consistently with her biased period 1 choice. The optimality condition for this case is $\alpha * \beta \geq 1-2 * l\left(m_{2}=\right.$ Blue, $m_{1}=$ Blue $)$.
} 